Original Article

\title{
A RETROSPECTIVE STUDY: THE OFF-LABEL USE OF ANTICONVULSANTS AT A PRIVATE HOSPITAL IN INDONESIA
}

\section{BANGUNAWATI RAHAJENG ${ }^{1,2^{*}}$, ZULLIES IKAWATI ${ }^{3}$, TRI MURTI ANDAYANI ${ }^{3}$, IWAN DWIPRAHASTO ${ }^{4}$}

1Doctoral Student at Faculty of Pharmacy, Universitas Gadjah Mada, Yogyakarta 55281, Indonesia, ${ }^{2}$ School of Pharmacy. Faculty of Medicine and Health Sciences, Universitas Muhammadiyah Yogyakarta, Indonesia, ${ }^{3}$ Pharmacology and Clinical Pharmacy Departement, Faculty of Pharmacy, Universitas Gadjah Mada, Yogyakarta, Indonesia, ${ }^{4}$ Pharmacology and Therapy Departement, Faculty of Medicine, Public Health and Nursing, Universitas Gadjah Mada, Yogyakarta, Indonesia Email: brahajeng@yahoo.com

Received: 20 Feb 2018 Revised and Accepted: 11 Apr 2018

\section{ABSTRACT}

Objective: Anticonvulsant is one class of drugs often used off-label. This study was conducted to investigate the prevalence and the indication of the off-label use of anticonvulsants in a private hospital in Java, Indonesia.

Methods: This was an observational study with a retrospective data collection in a private hospital in Java. Data were obtained on the prescription of anticonvulsants. Indications of the use of anticonvulsants were obtained from the medical records of patients who were prescribed anticonvulsants. The off-label use of anticonvulsants was defined a prescribing of medication outside the indication approved by The National Agency of Drug and Food Control Indonesia (NA-DFC). The use off-label of anticonvulsants was calculated by descriptive analysis and presented as a percentage.

Results: It showed that in one year there were 5,310 for 1,316 patients: of this 462 patients (35.11\%) were for an off-label use. The anticonvulsants used off-label were oxcarbazepine 67.27\% (37/55), carbamazepine 46.15\% (54/117), pregabalin45.45\% (60/132), phenytoin37.62\% (225/598), valproate $25.34 \%$ (37/109), and gabapentin 18.28\% (49/219). The highest off-label use of anticonvulsants was found in neurological and psychiatric disorders $67.32 \%(n=311)$, and on $97.19 \%$ of them were not supported by strong clinical evidence.

Conclusion: The off-label use of anticonvulsants occurred in one-third of patients receiving prescriptions of anticonvulsants, even though for most of them there was a lack of evidence. More attention must be paid to the efficacy and risk of side effects of the drug used.

Keywords: Anticonvulsants, Off-label, Private hospitals, Evidence-based medicine, Safe-prescribing

(C) 2018 The Authors. Published by Innovare Academic Sciences Pvt Ltd. This is an open access article under the CC BY license (http://creativecommons.org/licenses/by/4.0/) DOI: http://dx.doi.org/10.22159/ijpps.2018v10i5.25388

\section{INTRODUCTION}

Off-label prescribing refers to the use of a licensed drug that is different from the description in the product information [1] According to Stafford (2008), the off-label use of anticonvulsants was $74 \%$ [2]. Zito et al. (2006) found that anticonvulsants were given to children with psychiatric diagnoses without seizures (81\%), children with a diagnosis of seizures (19\%), and children with seizures and psychiatric diagnoses (71\%) [3]. An epidemiological study of the off-label use of anticonvulsants has also been carried out by Chen et al. (2005) in the Medicaid population of the U. S. state of Georgia. The results showed an off-label use of anticonvulsant of as much as $71.3 \%$ with gabapentin as the most widely prescribed off-label anticonvulsant $(86 \%)$. Four comorbidities of patients receiving off-label anticonvulsants are patients with diabetes mellitus, depression, schizophrenia, and pain. Neurologists were found to be the practitioners who most prescribe off-label anticonvulsants [4].

The off-label drug use is still debatable. This is because some offlabel drug use is not supported by strong evidence. This study was conducted to detect the off-label use of anticonvulsant. This research is needed as a baseline data on the off-label use of anticonvulsants, and is useful for further research, especially regarding the effectiveness and safety of its use. In Indonesia, there has never been a study on the off-label use of anticonvulsants. This study was the first research conducted to determine the off-label use of anticonvulsants in a private hospital in Java.

\section{MATERIALS AND METHODS}

\section{Methods}

This is an observational study with retrospective data collection. Data were obtained on the prescription of anticonvulsants in 2014 in a private hospital in Java. Indications of the use of anticonvulsants were obtained from the medical records of patients who were prescribed anticonvulsants. Medical records that could not be traced were excluded. The population in this study was made up of all patients (inpatients and outpatients) who were prescribed anticonvulsants in a private hospital in 2014.

Off-label use of anticonvulsants was determined by checking the diagnoses listed in the medical records on prescribing the anticonvulsants. This data was then matched to an approved indication by the National Agency of Drug and Food Control (NA-DFC) Indonesia in 2014, which is available at www. pionas. pom. go. id. The off-label use of anticonvulsants is said to have strong evidence if there are some randomized control trial, double-blind, with high-quality evidence (further research is very unlikely to change our confidence in the estimate of effect)[5]. Descriptive analysis is used to calculate the percentage of the off-label use of anticonvulsant.

\section{RESULTS}

In $2014,5,310$ prescriptions of anticonvulsants were given to 1,316 patients. The anticonvulsants used in the private hospital are phenytoin (PHT), valproate (VPA), gabapentin (GBP), pregabalin (PGB), carbamazepine (CBZ), and oxcarbazepine (OXC). The highest used anticonvulsant was phenytoin, followed by gabapentin, valproate, carbamazepine, pregabalin, and oxcarbazepine. The use of anticonvulsants in 2014 can be seen in table 1. 
Table 1: The use of anticonvulsants in 2014

\begin{tabular}{llllll}
\hline No & Drug & Prescription (n) & Patient (n) & On-label (\%) & Off-label (\%) \\
\hline 1 & *OXC & 213 & 55 & $18(37.72)$ & $37(67.28)$ \\
2 & PGB & 297 & 132 & $72(54.54)$ & $60(45.45)$ \\
3 & CBZ & 495 & 117 & $63(53.85)$ & $54(46.15$ \\
4 & PHT & 3038 & 598 & $373(62.37)$ & $225(37.62)$ \\
5 & VPA & 569 & 146 & $109(74.66)$ & $37(25.34)$ \\
6 & GBP & 698 & 268 & $219(81.72)$ & $49(18.28)$ \\
& Total & 5310 & 1316 & $854(64,89 \%)$ & $462(35,11 \%)$ \\
\hline
\end{tabular}

${ }^{*} \mathrm{OXC}=$ oxcarbazepine, $\mathrm{PGB}=$ pregabalin, $\mathrm{CBZ}=$ carbamazepine, $\mathrm{PHT}=$ phenytoin, $\mathrm{VPA}=$ valproate, $\mathrm{GBP}=$ gabapentin, table 2 shows the percentage of anticonvulsant use based on the indications written in the medical records. The indications listed are already indicative of the use off-label of anticonvulsants. Most off-label use of anticonvulsants in neurological and psychiatric cases (67.32\%).

Table 2: Off-label indication of anticonvulsants

\begin{tabular}{|c|c|c|c|c|c|c|c|c|c|}
\hline No & The use of anticonvulsants & $* \mathbf{O X C}$ & PGB & CBZ & PHT & VPA & GBP & Total & $\%$ \\
\hline 1 & $\begin{array}{l}\text { Neurologic and Psychiatric } \\
\text { disorder }\end{array}$ & 29 & 24 & 40 & 173 & 32 & 13 & 311 & 67.32 \\
\hline 2 & Rheumatologic disorder & 5 & 8 & 6 & 24 & & 19 & 62 & 13.42 \\
\hline 3 & Renal disorder & & 20 & & 3 & & 4 & 27 & 5.84 \\
\hline 4 & Infection diseases & 1 & & & 8 & 2 & 10 & 21 & 4.54 \\
\hline 5 & Cardiovascular disorder & & 3 & 3 & 7 & 2 & 2 & 17 & 3.68 \\
\hline 6 & Post Herpetic neuropathy & 1 & & 3 & & & & 4 & 0.87 \\
\hline 7 & Oncologic disorder & & & 1 & 2 & & & 3 & 0.65 \\
\hline 8 & Endocrine disorder & & 2 & & & 1 & & 3 & 0.65 \\
\hline 9 & Gastrointestinal disorder & 1 & 1 & & & & & 2 & 0.43 \\
\hline 10 & Dental & & 1 & & 1 & & & 2 & 0.43 \\
\hline 11 & Gynecologic disorder & & & & 1 & & & 1 & 0.22 \\
\hline 12 & Respiratory disorder & & & & 1 & & & 1 & 0.22 \\
\hline 13 & Immunologic disorder & & 1 & & & & & 1 & 0.22 \\
\hline \multirow[t]{2}{*}{14} & Other indications & & & 1 & 5 & & 1 & 7 & 1.51 \\
\hline & Total & 37 & 60 & 54 & 225 & 37 & 49 & 462 & 100 \\
\hline
\end{tabular}

*OXC=oxcarbazepine, $\mathrm{PGB}=$ pregabalin, $\mathrm{CBZ}=$ carbamazepine, $\mathrm{PHT}=$ phenytoin, $\mathrm{VPA}=$ valproate, $\mathrm{GBP}=$ gabapentin

\section{DISCUSSION}

The off-label drug use is legalized and clinically accepted. The Food and Drug Administration (FDA) as a drug regulatory authority in the United States legalizes off-label use under certain conditions. In Europe, the regulation of off-label drug prescribing is summarized by the European Medicines Agency's (EMA). Off-label prescribing provisions include strong scientific evidence or guaranteed safety of use by the consensus of professional organizations [6]. In Indonesia, there is no clear regulation regarding the off-label drug use. In 2014 Indonesia implemented a National Health Insurance (Jaminan Kesehatan Nasional $=\mathbf{J K N}$ ) in the form of health insurance for all its citizens and was managed by the Social Security Administering Agency (Badan Penyelenggara Jaminan Sosial =BPJS) [7]. In the JKN system, medicines prescribed that can be financed are medications registered by NADFC and listed in the National Formulary (Fornas). Fornas is a legal product (law) containing drugs legally registered by NADFC. Therefore, off-label drug uses cannot be used by patients who enter the JKN scheme. Even if doctors prescribe the drugs listed in the fornas with indications that are not or have not been approved by NADFC, of course, the drugs cannot be financed, or it is the responsibility of the RS to finance [8]. The results of this study indicate the presence of off-label drug use of anticonvulsants in Indonesia. The known evidence for the off-label drug use of anticonvulsants are as follows:

Table 1 show that the highest percentage of off-label use of anticonvulsants was for oxcarbazepine, although OXC has the lowest number of prescriptions. The off-label use of OXC is common in cases of trigeminal neuralgia. Oxcarbazepine $(10,11$-dihydro-10-oxo5Hdibenz (b. f) azepine-5-carboxamide) is a keto analogue of carbamazepine. OXC has the same mechanism as carbamazepine, as a sodium channel modulator, making it effective for epilepsy and trigeminal neuralgia. OXC is safer than CBZ with low risk of allergies and drug interactions [5]. The use of OXC on trigeminal neuralgia has been investigated by Gomez-Arguelles et al. (2008) with the results demonstrating a significant reduction in the frequency of pain and it was well tolerated by patients. OXC is recommended in patients who do not respond to CBZ. Carrazana found that the evidence supporting the use of OXC for trigeminal neuralgia is strong $[9,10]$. The use of OXC for other indications such as painful diabetic neuropathy, post-herpetic neuralgia, painful paroxysmal symptoms in multiple sclerosis, tremor, and migraine has already been investigated with a poor-moderate evidence level [5, 11-14]. In this study, the use of OXC in trigeminal neuralgia is categorized as offlabel use because the distribution license in Indonesia does not include an indication for OXC in trigeminal neuralgia.

The second most frequent off-label use of anticonvulsants is for pregabalin, widely used in patients with stroke and renal disorders. It is given to stroke patients for central post-stroke pain. The use of pregabalin in renal impairment is expected to prevent seizures (PGB is not the main therapy for preventing seizure). Pregabalin (3isobutyl- $\gamma$ aminobutyric acid) is a GABA analogue that does not function GABA neurotransmitter. Pregabalin is not binding to GABAA and GABAB. Pharmacologically, pregabalin related bonding results in the presynaptic alpha-2-delta subunit of $\mathrm{Ca}^{2+}$ channels [15]. According to Finnerup and Jensen (2007), there are two studies with randomized placebo-controlled trials on the use of pregabalin for neuropathic pain post stroke. Results from both studies showed that PGB is effective for central neuropathic post-stroke pain, and may improve the level of anxiety and sleep disorders [16]. Many studies have been conducted on the analgesic effect of pregabalin including pregabalin for acute and chronic pain, evaluation of safety and efficacy of pregabalin in geriatric patients, pregabalin for DPN and PHN, pregabalin for bone cancer pain, pregabalin for postoperative pain [17-20]. The study of the adverse effects of pregabalin as an analgesic has also been done. The side effects include somnolence, dizziness, peripheral oedema, and dry mouth [21]. The FDA has licensed the use of pregabalin for the treatment of neuropathic pain associated with diabetic peripheral neuropathy (DPN), post-herpetic neuralgia (PHN), and adjunctive therapy in an adult partial seizure. 
The FDA has not given permission for the treatment of generalized anxiety disorder (GAD) [15]. The distribution license in Indonesia is for peripheral neuropathic pain and adjunctive therapy for partial seizures with or without secondary generalization.

In this study, the off-label use of carbamazepine was found for central post-stroke pain. Other users with a smaller percentage were for DPN, PHN, herniated nucleus pulposus (HNP), and joint pain. The mechanisms of carbamazepine for neuropathic pain is by blocking the sodium channels that can reduce the excitability of nerve cells [22]. The mechanism for reducing nociceptive pain is estimated from the ability of carbamazepine to intervene on -aminobutyric acid (GABA)-ergic and somatostatinergic systems. Other mechanisms, with low evidence, are by blocking calcium channels and excitatory amino acid [23]. Research on the use of carbamazepine in other than trigeminal neuralgia has lacked evidence. Regarding central poststroke pain, there is only one study, while on DPN there is some research but also a low evidence level, similarly for PHN [24, 25]. Carbamazepine in Indonesia has a distribution license for the prophylaxis of indications of manic-depressive disorder that is not responsive to lithium, all types of epilepsy, except petit mal, and trigeminal neuralgia.

The off-label use of phenytoin occurs in the case of petit mal epilepsy or absence seizures. Phenytoin is an old anticonvulsant and is widely used to control seizures by stabilizing the mechanism of sodium channels. Phenytoin is also known to be used in anxiety and mood stabilizing. Phenytoin and CBZ were the anticonvulsants that were first examined in trigeminal neuralgia [26]. Some use of phenytoin in neuropathic pain has less powerful evidence or no evidence [27]. Phenytoin is contraindicated in petit mal because it can cause seizures and is ineffective [28]. The NA-DFC distribution license granted for phenytoin includes therapy for all types of epilepsy, except for petit mal and status epilepticus.

This study found that valproate was used in cephalgia, vertigo, syncope, and schizophrenia. Valproate is thought to have a GABA-ergic neurotransmission influence mechanism and also the blockade of the sodium channels. Increased GABA levels and cell membrane stability are thought to reduce pain signals in the brain [29]. A review by Vargas-Espinosa et al. mentions the use of valproate for PHN and makes a recommendation for a high-quality randomized controlled trial [29]. Studies have been conducted on valproate for indications other than epilepsy, on migraine, alcohol dependence, bipolar disorders, fibromyalgia, and schizophrenia with low evidence [29-31].

In previous studies, gabapentin is an anticonvulsant that is often used off-label. During its development, gabapentin research on indications outside epilepsy was conducted with strong evidence, so the industry finally registered gabapentin to the drug and food authority bodies, so that gabapentin became on-label for any neuropathic pain. Gabapentin has strong anticonvulsant and analgesic effects through the GABA-ergic transmission modulation mechanism. Another mechanism is the blockade of the sodium channels [32]. The off-label use of gabapentin in this study was found for nociceptive pain in rheumatism, joint pain, osteoarthritis, phlebitis, and fracture. Gabapentin in nociceptive pain has been studied in post-operative pain management with good efficacy, and in benign nociceptive pain [32, 33]. In Indonesia, the gabapentin permit allows adjunctive therapy for partial epilepsy with or without a generalized seizure, which cannot be controlled with other antiepilepsy medication, and for neuropathic pain.

The indication of the off-label use of anticonvulsants can be seen in table 2. The most common off-label use of anticonvulsants is in neurological and psychiatric, then in rheumatic and renal disorder. In neurological cases, off-label use occurs in cases of neuropathy pain, stroke, trigeminal neuralgia, cephalgia, and petit mal. Research conducted by Jena et al. in 2013-2014 mentions several anticonvulsants prescribed for neuropathic pain, namely carbamazepine, gabapentin, pregabalin, lamotrigine, oxcarbazepine, topiramate, and valproate [34]. Some anticonvulsants prescribed for neuropathic pain are usually used in the long term. It should be noted, because based on research Varghese et al. the chronic use of anticonvulsant cause osteoporosis and anaemia significantly [35]. While in rheumatic disease, anticonvulsants are used in osteoarthritis, fracture, and joint pain. In the case of renal disorders, the use of anticonvulsants is not clear, possibly associated with preventing seizure in hemodialysis patients. Of 462 off-label prescriptions, only $13(2.81 \%)$ had strong evidence, namely, OXC in trigeminal neuralgia. While the remaining 449 (97.19\%) have low evidence or lack of evidence. From the study, anticonvulsants were known to cause adverse drug reaction (ADR) by $36 \%$ of 132 ADR events. ADR was found in carbamazepine (16.6\%) and pregabalin (9.8\%). Common ADRs are nausea, dizziness, and drowsiness [34].

\section{Limitation}

This was a retrospective study at one private hospital in Java, and the result may not be generalizable for another hospital or another country. This study could not determine why physicians prescribed a drug for a particular indication. However, the findings provide important information for future research, because nearly all the offlabel uses of anticonvulsants lack evidence.

\section{CONCLUSION}

The off-label use of anticonvulsants occurred in one-third of patients receiving prescriptions of anticonvulsants, even though for most of them there was a lack of evidence. More attention must be paid to the efficacy and risk of side effects of the drug used.

\section{ACKNOWLEDGMENT}

Dra. Endang Yuniarti, M. Kes., Apt, pharmacists of PKU Muhammadiyah Hospital Yogyakarta.

\section{AUTHORS CONTRIBUTIONS}

The first author contributed to all of the writing processes. The second, third and fourth authors contribute to the concept, design, definition of intellectual content, manuscript preparation, editing, review, and guarantor of the manuscript.

\section{CONFLICT OF INTERESTS}

\section{There is no conflict of interest}

\section{REFERENCES}

1. Le Jeunne C, Billon N, Dandon A. Participants of roundtable $\mathrm{N}^{\circ}$ 3 of Giens XXVIII:, Berdaï D, Adgibi Y, et al. Off-label prescriptions: how to identify them, frame them, announce them and monitor them in practice? Therapie 2013;68:233-9.

2. Stafford RS. Regulating off-label drug use-rethinking the role of the FDA. N. Engl J Med 2008;358:1427-9.

3. Zito JM, Safer DJ, Gardner JF, Soeken K, Ryu J. Anticonvulsant treatment for psychiatric and seizure indications among youths. Psychiatr Serv [Internet] 2006; Available from: http://ps.psychiatryonline.org/doi/abs/10.1176/ps.2006.57.5. 681. [Last accessed on 12 Oct 2016].

4. Chen H, Deshpande AD, Jiang R, Martin BC. An epidemiological investigation of off-label anticonvulsant drug use in the georgia medicaid population. Pharmacoepidemiol Drug Saf 2005; 14:629-38.

5. Zhou M, Chen N, He L, Yang M, Zhu C, Wu F. Oxcarbazepine for neuropathic pain [Internet]. In: The Cochrane Collaboration. editor. Cochrane Database of Systematic Reviews. Chichester. UK: John Wiley and Sons, Ltd; 2013. Available from: http://doi.wiley.com/10.1002/14651858.CD007963.pub2. [Last accessed on 20 Nov 2015]

6. Lenk C, Duttge G. Ethical and legal framework and regulation for off-label use: European perspective. Ther Clin Risk Manag 2014;10:537-46.

7. Presiden RI. Undang-undang Republik Indonesia No. 40 Tahun 2004 tentang Sistem Jaminan Sosial Nasional-[PERATURAN]; 2004.

8. Kesehatan IK. Peraturan Menteri Kesehatan Republik Indonesia Nomor 71 Tahun 2013 Tentang Pelayanan Kesehatan Pada Jaminan Kesehatan Nasional-[PERATURAN]; 2013.

9. Carrazana E, Mikoshiba I. Rationale and evidence for the use of oxcarbazepine in neuropathic pain. J Pain Symptom Manage 2003;25:S31-5.

10. Gomez-Arguelles JM, Dorado R, Sepulveda JM, Herrera A, Gilo Arrojo F, Aragón E, et al. Oxcarbazepine monotherapy in 
carbamazepine-unresponsive trigeminal neuralgia. J Clin Neurosci 2008;15:516-9.

11. Dogra S, Beydoun S, Mazzola J, Hopwood M, Wan Y. Oxcarbazepine in painful diabetic neuropathy: a randomized, placebo-controlled study. Eur J Pain Lond Engl 2005;9:543-54.

12. Raj V, Landess JS, Martin PR. Oxcarbazepine uses in essential tremor. PubMed-NCBI. Ann Pharmacother 2006;40:1876-9.

13. Silberstein S, Saper J, Berenson F, Somogyi M, McCague K, D’Souza J. Oxcarbazepine in a migraine headache a double-blind, randomized, placebo-controlled study. Neurology 2008;70:548-55.

14. Solaro C, Restivo D, Mancardi GL, Tanganelli P. Oxcarbazepine for treating paroxysmal painful symptoms in multiple sclerosis: a pilot study. Neurol Sci 2007;28:156-8.

15. Shneker BF, McAuley JW. Pregabalin: a new neuromodulator with broad therapeutic indications. Ann Pharmacother 2005;39:2029-37.

16. Finnerup NB, Jensen TS. Clinical use of pregabalin in the management of central neuropathic pain. Neuropsychiatr Dis Treat 2007;3:885.

17. Gilron I, Wajsbrot D, Therrien F, Lemay J. Pregabalin for peripheral neuropathic pain: a multicenter, enriched enrollment randomized withdrawal placebo-controlled trial. Clin J Pain 2011;27:185-93.

18. Moore RA, Straube S, Wiffen PJ, Derry S, McQuay HJ. Pregabalin for acute and chronic pain in adults [Internet]. In: The Cochrane Collaboration. editor. Cochrane Database of Systematic Reviews. Chichester, UK: John Wiley and Sons, Ltd; 2009. Available from: http://doi.wiley.com/10.1002/ 14651858.CD007076.pub2. [Last accessed on 26 Feb 2015]

19. Singla, Chelly J, Lionberger D, Gimbel J, Sanin L, Sporn J, et al. Pregabalin for the treatment of postoperative pain: results from three controlled trials using different surgical models. J Pain Res 2014;8:9-20.

20. Sjolund KF, Yang R, Lee KH, Resnick M. Randomized study of pregabalin in patients with cancer-induced bone pain. Pain Ther 2013;2:37-48.

21. Toth C. Pregabalin: latest safety evidence and clinical implications for the management of neuropathic pain. Ther Adv Drug Saf 2014;5:38-56.

22. Ambrosio AF, Soares-Da-Silva P, Carvalho CM, Carvalho AP. Mechanisms of action of carbamazepine and its derivatives, oxcarbazepine. Neurochem Res 2002;27:121-30.

23. Basbaum AI, Bautista DM, Scherrer G, Julius D. Cellular and molecular mechanisms of pain. Cell 2009;139:267-84.

24. Jia H, Li Q, Song D, An Z, Liu Y, Ran X, et al. Effects of veniafaxine and carbamazepine for painful peripheral diabetic neuropathy: a randomized, double-blind and double-dummy, controlled multi-center trial. Chin J Evid Based Med 2006;6:321-7.

25. Wiffen PJ, Derry S, Moore RA, McQuay HJ. Carbamazepine for acute and chronic pain in adults [Internet]. In: The Cochrane Collaboration. editor. Cochrane Database of Systematic Reviews. Chichester, UK: John Wiley and Sons, Ltd; 2011. Available from: http://doi.wiley.com/10.1002/14651858. CD005451. pub2. [Last acessed on13 Oct 2016].

26. Jensen TS. Anticonvulsants in neuropathic pain: rationale and clinical evidence. Eur J Pain Lond Engl 2002;6 Suppl A:61-8.

27. Birse F, Derry S, Moore RA. Phenytoin for neuropathic pain and fibromyalgia in adults [Internet]. In: The Cochrane Collaboration. editor. Cochrane Database of Systematic Reviews. Chichester, UK: John Wiley and Sons, Ltd; 2012. Available from: http://doi.wiley.com/10.1002/14651858. CD009485.pub2. [Last accessed on 05 Mar 2015]

28. Tracy Glauser, Elinor Ben-Menachem, Blaise Bourgeois, Avital Cnaan, Carlos Guerreiro, Reetta Ka, et al. Guidelines-epilepsia12074-2013.pdf. Epilepsia; 2013. p. 1-13.

29. Vargas Espinosa M, Sanmarti Garcia G, Vazquez Delgado E, Gay Escoda C. Antiepileptic drugs for the treatment of neuropathic pain: a systematic review. Med Oral Patol Oral Cirugia Bucal 2012;17:e786-93.

30. Gill D, Derry S, Wiffen PJ, Moore RA. Valproic acid and sodium valproate for neuropathic pain and fibromyalgia in adults [Internet]. In: The Cochrane Collaboration. editor. Cochrane Database of Systematic Reviews. Chichester, UK: John Wiley and Sons, Ltd; 2011. Available from: http://doi.wiley.com/ 10.1002/14651858.CD009183.pub2. [Last accessed on 05 Mar 2015].

31. Horowitz E, Bergman LC, Ashkenazy C, Moscona Hurvitz I, Grinvald Fogel H, Magnezi R. Off-label use of sodium valproate for schizophrenia. PLoS One 2014;9:e92573.

32. Chang CY, Challa CK, Shah J, Daniel E. Gabapentin in acute postoperative pain management. BioMed Res Int; 2014. p. 1-7.

33. McCleane GJ. Gabapentin reduces chronic benign nociceptive pain: a double-blind, placebo-controlled cross-over study. Pain Clin 2000;12:81-5.

34. Jena SS, Jena M, Patro N, Mishra S, Panda M, Dash M. Patterns of prescription and adr monitoring of drugs in the management of neuropathic pain in a tertiary care teaching hospital. Int J Pharm Pharm Sci 2014;6:246-51.

35. Varghese AP, Philip B, Krihnakumar M, Kuriakose F, Rodrigues PA. Assessment of osteoporosis and anaemia risk in patients on anticonvulsant therapy. Int J Pharm Pharm Sci 2016;8:404-8. 